\title{
Analisis Tingkat Kelelahan Pada Pembatik Batik Tulis Menggunakan SOFI (Swedish Occupational Fatigue Index)
}

\author{
Sony Haryanto ${ }^{1}$, Renny Septiari ${ }^{2}$, Mochammad Rofieq ${ }^{3}$ \\ ${ }_{1,2}$ Jurusan Teknik Industri, Institut Teknologi Nasional Malang \\ ${ }^{3}$ Jurusan Teknik Industri, Universitas Merdeka Malang \\ *Korespondensi Penulis, E-mail: rennyseptiari@lecturer.itn.ac.id
}

Diterima : 4 Oktober 2020

Direvisi : 26 Oktober 2020

Disetujui : 14 November 2020

Abstrak

Setiap kelelahan yang terjadi berpengaruh secara berbeda terhadap masing-masing orang sesuai dengan jenis pekerjaan yang dilakukan, baik berpengaruh secara mental maupun fisik. Kelelahan adalah suatu mekanisme perlindungan agar tubuh terhindar dari kerusakan yang lebih lanjut, sehingga dibutuhkan waktu untuk istirahat agar terjadi pemulihan pada kondisi tubuh yang lelah. Tujuan dari penelitian ini adalah untuk menentukan hubungan antara tingkat kelelahan dengan produktivitas para pembatik. Penelitian ini dilakukan di UKM Batik Erna di Mojokerto. Objek dalam penelitian ini yaitu pembatik batik tulis yang bekerja lebih dari 5 tahun di UKM batik Erna. Uji statistik yang digunakan adalah uji validitas dan reliabilitas, dan uji Korelasi. Pengukuran tingkat kelelahan menggunakan kuesioner Swedish Occupational Fatigue Index (SOFI)

Hasil penelitian menunjukkan bahwa terdapat hubungan yang berpengaruh signifikan antara tingkat kelelahan dengan produktivitas yang dialami oleh para pembatik batik tulis menurut uji korelasi yang dilakukan dengan hasil 0.993. Sehingga semakin tinggi tingkat kelelahan yang dialami maka semakin menurun produktivitas yang dihasilkan.

Kata kunci: kelelahan, pembatik, produktivitas, SOFI.

\section{Pendahuluan}

Batik adalah Warisan Kemanusiaan untuk Budaya Lisan dan Nonbendawi demikian bunyi pengakuan dari UNESCO pada tanggal 2 Oktober 2009 tentang batik sehingga tak heran industri batik saat ini berkembang dengan pesat dan lebih bercorak ragamnya. Adapun jenis batik yang dikukuhkan adalah jenis batik tulis, dimana proses pengerjaannya berupa kain yang dihias tekstur dan corak batik menggunakan tangan. Pembuatan batik jenis ini bisa memakan waktu $1-2$ bulan, aktivitas pembatikan bisa dikategorikan sebagai aktivitas yang memiliki gerakan berulang-ulang [1], beban bervariasi dari motif batik, gerakan translasi, rotasi, kombinasi translasi dan rotasi dengan posisi duduk statis [2] serta posisi awkward (tidak nyaman) sehingga rentan mengalami kelelahan pada anggota tubuh [3]. Kelelahan ini timbul karena banyak dari pembatik melakukan sikap kerja yang tidak benar seperti membungkuk, miring, posisi berdekatan antar pekerja sehingga tidak didapat posisi yang nyaman dalam bekerja. Adapun penyebab lain timbulnya kelelahan pada anggota tubuh yang dialami adalah seperti faktor usia, beban kerja, cara kerja dan lamanya waktu dalam bekerja yang menyebabkan kebosanan [4]. Adapun kelelahan yang pada akhirnya menimbulkan nyeri sering terjadi pada pembatik batik tulis seperti nyeri punggung, nyeri leher, nyeri pada pergelangan tangan, siku dan kaki. Ada 4 faktor yang dapat meningkatkan timbulnya nyeri ataupun keluhan yang dirasakan yaitu postur yang tidak alamiah, tenaga yang berlebihan, pengulangan berkali-kali, dan lamanya waktu kerja. Akibatnya konsentrasi dalam bekerja terganggu, timbullah kelelahan yang pada akhirnya akan menurunkan tingkat produktivitas. Tingginya tingkat cidera atau kecelakaan kerja selain merugikan secara langsung yaitu sakit yang diderita oleh pekerja, kecelakaan tersebut juga akan berdampak buruk terhadap kinerja unit usaha. 

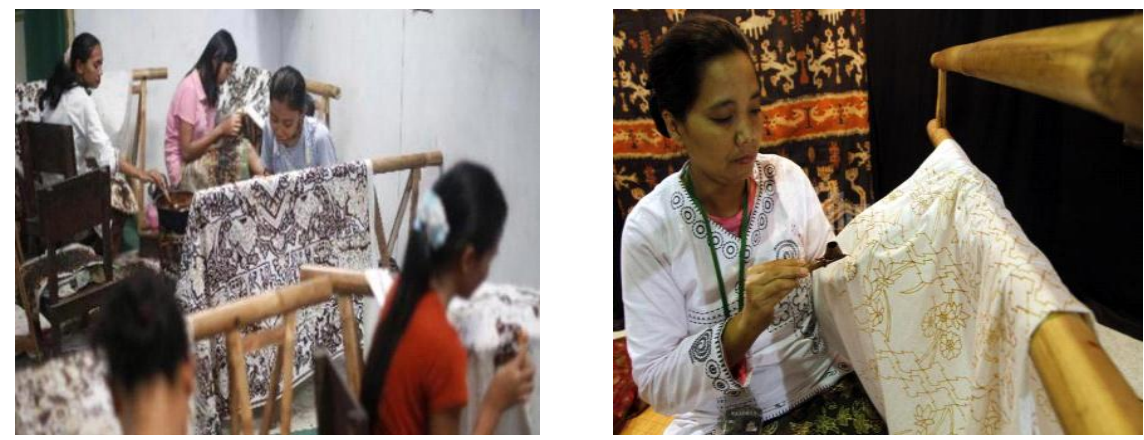

Gambar 1. Posisi Membatik

Salah satu gejala gangguan kesehatan pada tenaga kerja yang timbul akibat pekerjaan adalah kelelahan. Kelelahan kerja merupakan masalah yang sering dijumpai pada tenaga kerja. Kelelahan kerja merupakan masalah penting yang perlu ditanggulangi dengan baik sebab dapat menyebabkan berbagai masalah seperti kehilangan efisiensi dalam bekerja, penurunan produktivitas dan kapasitas kerja serta kemampuan kesehatan dan kemampuan bertahan tubuh yang menyebabkan kecelakaan kerja. Kelelahan juga merupakan penyebab utama terjadinya kecelakaan kerja dan akan berpengaruh terhadap produktivitas. Penelitian yang dilakukan oleh [3], menyebutkan bahwa kelelahan secara langsung dipengaruhi oleh stres kerja, konflik kerja, lingkungan fisik serta kapasitas kerja. Bahwa kelelahan ditandai dengan melemahnya tenaga kerja dalam melakukan pekerjaan atau kegiatan sehingga akan meningkatkan kesalahan dalam melakukan pekerjaan dan akibat fatalnya yaitu terjadinya kecelakaan kerja [5].

Data dari [6], menyebutkan sebanyak dua juta pekerja menjadi korban setiap tahun karena kecelakaan kerja akibat faktor kelelahan. Penelitian yang dilakukan [6], menjelaskan bahwa sebanyak 58.118 sampel dari 18.828 sampel $(32,8 \%)$ di antaranya mengalami kelelahan dan berpengaruh pada produktivitas kerja. Produktivitas di Indonesia sendiri masih relatif rendah jika dibandingkan dengan 3 negara kompetitor lainnya di ASEAN. Data produktivitas tahun 2013 yang dirilis oleh Asian productivity Organization menyebutkan bahwa produktivitas tenaga kerja Indonesia berada di bawah rata-rata negara ASEAN yaitu sebesar 10.700 dollar AS atau 117,7 juta.

Kelelahan tenaga kerja bagian pencantingan di UKM Batik Erna juga disebabkan oleh pekerjaan yang bersifat monoton. Keadaan monoton ini berhubungan dengan gerakan-gerakan yang dilakukan pekerja dalam melakukan aktivitas pekerjaannya saat mencanting yang dilakukan setiap hari secara berulang dan kurang bervariasi.[7], mengatakan bahwa kelelahan erat kaitannya dengan perasaan bosan akibat pekerjaan yang monoton. Pekerjaan sama yang dilakukan berulang-ulang dari hari ke hari tanpa adanya variasi dapat menimbulkan rasa jemu, bosan dan cepat lelah. [8], mengatakan bahwa kondisi kerja yang berulang-ulang dapat menimbulkan suasana monoton yang berakumulasi menjadi rasa bosan, dimana rasa bosan dikategorikan sebagai kelelahan. Jam kerja yang berlebihan dan jam kerja lembur di luar batas kemampuan dapat mempercepat timbulnya kelelahan [9], menurunkan ketepatan, kecermatan dan ketelitian kerja. Penelitian yang dilakukan [10] menyatakan bahwa pekerjaan monoton yang dilakukan secara berulang-ulang menyebabkan timbulnya kelelahan.

Berdasarkan keterangan di atas didapatkan masukan atau gambaran bahwa pekerjaan mencanting/membatik begitu melelahkan sehingga apabila dibiarkan terus menerus akan menimbulkan keluhan atau nyeri diseluruh anggota tubuh terutama bagian otot. Sehingga dapat ditentukan bahwa tujuan dari penelitian ini adalah menentukan hubungan antara tingkat kelelahan dengan produktivitas para pembatik batik tulis. 


\section{Metodologi Penelitian}

Penelitian ini merupakan penelitian observasional yaitu dilakukan dengan cara mengamati objek penelitian tanpa memberikan perlakuan. Menurut waktu pelaksanaannya, penelitian ini merupakan penelitian cross sectional karena data tentang variabelnya diperoleh pada satu waktu.

Adapun partisipan yang ikut berperan dalam penelitian ini adalah para pembatik batik tulis yang berjumlah 4 orang dan berjenis kelamin wanita. Mereka rata-rata telah bekerja selama lebih dari 5 tahun sebagai pembatik batik tulis bagian pencantingan. Dipilih tenaga kerja yang bekerja lebih dari 5 tahun karena pekerjaan pencantingan memerlukan ide dan kreativitas tinggi untuk pengerjaannya. Karena selain kain mori telah terdapat pola tetapi untuk menghasilkan batik tulis yang berkualitas seorang pembatik harus memiliki pengalaman untuk menyelesaikan proses pencantingan suatu kain batik.

Variabel pada penelitian ini yaitu kelelahan subjektif dan produktivitas tenaga kerja. Sumber data yang digunakan adalah data primer dengan cara wawancara menggunakan kuesioner serta pengukuran secara langsung. Data sekunder digunakan untuk mendukung adanya data primer. Instrumen dalam penelitian ini adalah kuesioner Swedish Occupational Fatigue Index (SOFI) untuk mengukur kelelahan subjektif. Swedish Occupational Fatigue Index berisi 23 pertanyaan yang berisi 5 pertanyaan tentang kurangnya energi, 5 pertanyaan tentang aktivitas fisik, 4 pertanyaan tentang ketidaknyamanan fisik, 4 pertanyaan tentang kurang motivasi dan 5 pertanyaan tentang kantuk [11]. Sedangkan untuk data produktivitas pengukuran menggunakan stopwatch, dimana pengambilan data diambil dari awal pencantingan sampai proses pencantingan selesai dalam satu lembar kain sesuai pola yang yang ada. Adapun disini pola batik yang akan digunakan sebagai acuan tingkat produktivitas (kecepatan mencanting) seperti pada gambar 2 .

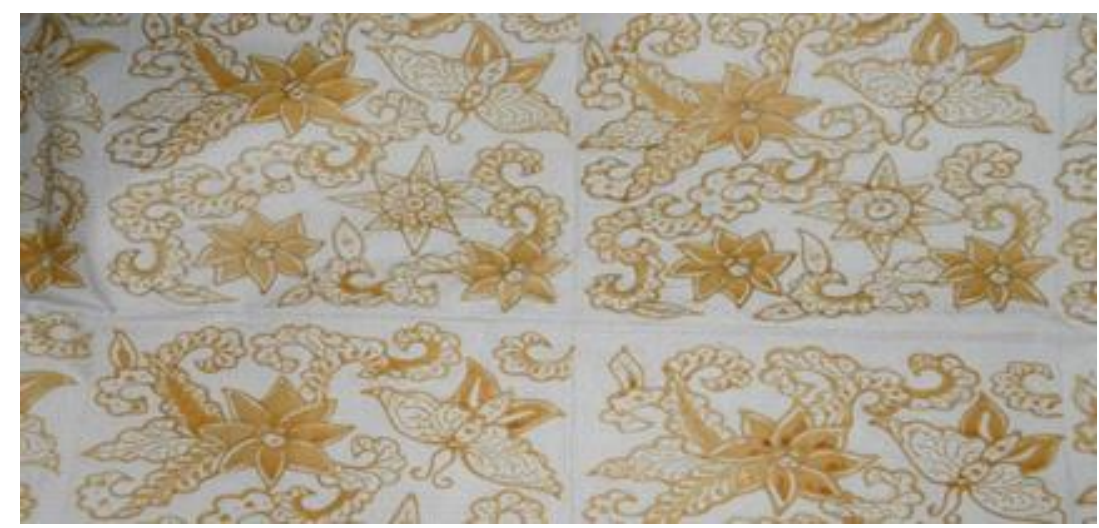

Gambar 2. Motif Bunga

\section{Pengumpulan Data}

Pengumpulan data dilakukan melalui observasi (pengamatan langsung) untuk data produktivitas menggunakan stopwatch dengan mencatat tingkat kecepatan pembatik dalam menyelesaikan pencantigan dalam satu kotak (satuan hasil pembatikan diukur dengan 'kotak', dimana 1 kotak memiliki ukuran $25 \times 25 \mathrm{~cm}^{2}$, dan total terdapat 16 kotak dalam sehelai kain) dan kuesioner SOFI untuk data tingkat kelelahan. menggunakan skala likert dengan rentang 1 sampai 6 (tidak terjadi / tidak dirasa - sering terjadi / sering dirasa), Adapun penjelasan untuk data yang diperlukan untuk penelitian dapat dilihat dari Tabel 1. 
Tabel 1. Data untuk Penelitian

\begin{tabular}{|l|l|l|}
\hline $\begin{array}{l}\text { Data Yang } \\
\text { Dibutuhkan }\end{array}$ & Teknik Pengumpulan & \multicolumn{1}{c|}{ Output yang Diharapkan } \\
\hline $\begin{array}{l}\text { Waktu } \\
\text { penyelesaian 1 } \\
\text { kotak } \\
\text { pencantingan }\end{array}$ & $\begin{array}{l}\text { Pengamatan } \\
\text { langsung dengan } \\
\text { stopwatch }\end{array}$ & $\begin{array}{l}\text { Waktu yang dibutuhkan untuk } \\
\text { menyelesaikan pencantingan dalam } \\
\text { satu lembar kain yang telah diberi pola } \\
\text { gambar }\end{array}$ \\
\hline $\begin{array}{l}\text { Jawaban dari } \\
\text { kuesioner SOFI }\end{array}$ & $\begin{array}{l}\text { Menanyakan } \\
\text { langsung kepada } \\
\text { pembatik }\end{array}$ & $\begin{array}{l}\text { Diketahui data yang merupakan } \\
\text { jawaban dari kuesioner SOFI dari } \\
\text { masing-masing responden/pembatik }\end{array}$ \\
\hline
\end{tabular}

\section{Populasi dan Sampel}

Populasi penelitian ini adalah para pembatik yang berjumlah 4 orang. Sampel adalah bagian atau wakil populasi yang diteliti. Sampel merupakan sebagian dari populasi yang memiliki karakteristik yang relatif sama dan dianggap bisa mewakili populasi [12]. Besaran atau ukuran sampel ini sangat tergantung dari besaran tingkat ketelitian atau kesalahan yang diinginkan peneliti [13]. Dalam penelitian ini, sampel diambil sebanyak 4 orang pembatik dengan masa kerja diatas 5 tahun. Hal dilakukan karena disesuaikan dengan kondisi lapangan dan cara kerja, yang apabila diambil pembatik yang mempunyai pengalaman dibawah 5 tahun dikhawatirkan hasil yang didapat tidak sesuai dengan yang diharapkan dan waktu penyelesaian tidak tepat waktu. Karena dalam penelitian ini (Eksperimen Quasi) motif yang digunakan untuk menguji keahlian pembatik lumayan sulit yaitu motif Bunga. Sehingga diperlukan keahlian yang sesuai dengan masa kerja agar hasil yang didapat baik dan tidak banyak cacat.

\section{Hasil Penelitian dan Pembahasan}

\subsection{Hasil Penelitian}

Data waktu penyelesaian pencantingan untuk satu lembar kain yang telah diberi pola total berjumlah 16 kotak, dan hasil tingkat kelelahan dari tiap-tiap responden/pembatik berdasarkan kuesioner SOFI yang mereka isi ditampilkan pada tabel 2.

Tabel 2. Data Waktu Penyelesaian dan Tingkat Kelelahan

\begin{tabular}{|c|c|c|}
\hline $\begin{array}{c}\text { Responden / } \\
\text { Pembatik }\end{array}$ & $\begin{array}{c}\text { Waktu } \\
\text { Penyelesaian } \\
\text { (menit) }\end{array}$ & $\begin{array}{c}\text { Rata-rata Tingkat } \\
\text { Kelelahan } \\
(\%)\end{array}$ \\
\hline Nurul & 264 & 23,74 \\
\hline Suparti & 306 & 27,52 \\
\hline Kunanti & 280 & 25,18 \\
\hline Sri & 262 & 23,56 \\
\hline Total & 1.112 & 100 \\
\hline
\end{tabular}

(Sumber olahan)

\subsection{Pembahasan}

Pada tabel 2, telah diperoleh hasil dari waktu penyelesaian dan rata-rata tingkat kelelahan dari kuesioner SOFI. Sebelum dilakukan analisis lebih lanjut, terlebih dulu 
akan dilakukan uji validitas dan reliabilitas untuk hasil jawaban dari kuesioner SOFI yang diberikan.

\subsubsection{Uji Validitas}

Pengujian validitas digunakan untuk mengukur sah/valid atau tidaknya butir kuesioner. Kuesioner dikatan valid jika butir pertanyaan kuesioner mampu untuk mengungkapkan sesuatu yang akan diukur. Dalam menentukan signifikan atau tidak signifikan dengan mrmbandingkan nilai $r$ hitung dengan nilai $r$ tabel degree of freedom $=\mathrm{n}-\mathrm{k}$, dan daerah sisi pengujian dengan alpha 0,05. Jika $r$ hitung tiap butir pertanyaan bernilai positif dan lebih besar terhadap $r$ tabel (lihat corrected item-total correlation) maka butir pertanyaan tersebut dikatakan valid. Hasil uji validitas dari kuesioner SOFI dari 23 pertanyaan dinyatakan valid karena rhitung $>$ rtabel 0,413 , dari keseluruhan butir pertanyaan.

\subsubsection{Uji Reliabilitas}

Secara umum reliabilitas dapat diartikan sebagai sesuatu hal yang dapat dipercaya atau suatu keadaan yang dapat dipercaya. Dalam analisis statistik suatu penelitian, uji reliabiltas berfungsi untuk mengetahui tingkat konsistensi suatu angket yang digunakan pada suatu penelitian, sehingga angket tersebut dapat dihandalkan untuk mengukur variabel penelitian, walaupun penelitian tersebut dilakukan secara berulang-ulang dengan angket dan kuesioner yang sama.

Tabel 3. Hasil Uji Reliabilitas

\begin{tabular}{|c|c|}
\hline $\begin{array}{c}\text { Nilai Cronbach's } \\
\text { Alpha }\end{array}$ & 0.899 \\
\hline
\end{tabular}

Karena nilai Cronbach's Alpha $0.899>0,6$ maka dapat disimpulkan bahwa data reliable atau konsisten.

\subsubsection{Uji Korelasi}

Analisis korelasi adalah teknik analisis yang digunakan untuk mengukur kuat lemahnya hubungan dua variabel. Variabel ini terdiri dari variabel bebas dan tergantung. Besarnya hubungan berkisar antara 0-1. Jika mendekati angka 1 berarti hubungan kedua variabel semakin kuat, demikian juga sebaliknya jika mendekati angka 0 berarti hubungan kedua variabel semakin lemah. Teknik korelasi dalam SPSS dibagi menjadi 3 yaitu : bivariate, parsial dan distance.

Korelasi pearson digunakan untuk mengetahui ada tidaknya hubungan antara 2 variabel, yaitu variabel bebas dan variabel tergantung yang berskala interval atau rasio (parametrik) yang dalam SPSS disebut scale. Asumsi dalam korelasi Pearson, data harus berdistribusi normal. Korelasi dapat menghasilkan angka positif $(+)$ dan negatif (). Jika angka korelasi positif berarti hubungan bersifat searah. Searah artinya jika variabel bebas besar, variabel tergantung semakin besar. Jika menghasilkan angka negatif berarti hubungan bersifat tidak searah. Tidak searah artinya jika nilai variabel bebas besar, variabel tergantung semakin kecil. angka korelasi berkisar antara 0-1.

Tabel 4. Hasil Uji Korelasi Pearson

\begin{tabular}{|r|r|r|r|}
\hline \multicolumn{2}{|c|}{} & Kelelahan & Produktivitas \\
\hline Kelelahan & $\begin{array}{c}\text { Pearson } \\
\text { Correlation }\end{array}$ & 1 & $.993^{* *}$ \\
\cline { 2 - 4 } & Sig. (2-tailed) & & .007 \\
\cline { 2 - 4 } & $\mathrm{N}$ & 4 & 4 \\
\hline
\end{tabular}




\begin{tabular}{|l|r|r|r|}
\hline \multirow{2}{*}{ Produktivitas } & $\begin{array}{c}\text { Pearson } \\
\text { Correlation }\end{array}$ & $.993^{* *}$ & 1 \\
\cline { 2 - 4 } & Sig. (2-tailed) & .007 & 4 \\
\cline { 2 - 4 } & $\mathrm{N}$ & 4 & 4 \\
\hline
\end{tabular}

Dari tabel 4 dapat diketahui bahwa nilai signifikansi $p$-value sebesar 0.007 $(<0.05)$, kesimpulannya ada hubungan antara tingkat kelelahan dan produktivitas. Besarnya korelasi adalah 0.993 .

Seperti penelitian yang dilakukan [14], menerangkan bahwa terdapat hubungan hubungan antara kelelahan kerja dengan produktivitas kerja pada tenaga kerja bagian tenun di PT. ALKATEX Tegal. Tingkat kelelahan dipengaruhi oleh beberapa faktor seperti faktor individu, faktor pekerjaan, dan faktor lingkungan kerja [15]. Lingkungan kerja terkait dengan fasilitas kerja yang nyaman yang dapat meningkatkan produktivitas pekerja [16].

Sehingga dapat dijelaskan bahwa produktivitas pembatik sangat dipengaruhi oleh tingkat kelelahan yang terjadi pada dirinya. Semakin tinggi kelelahan yang dialami maka akan semakin menurun pula tingkat produkvitas yang dihasilkan dan tentu saja ini akan berpengaruh terhadap hasil pencantingan yang dikerjakan. Untuk itu perlu adanya upaya agar tingkat kelelahan ini dapat diatasi sehingga kinerja para pembatik batik tulis dapat meningkat disamping menjaga kesehatan para pembatik.

\section{Kesimpulan}

Dari hasil pengamatan dan analisis data dapat diketahui bahwa pekerjaan pencantingan yang dilakukan oleh para pembatik batik tulis dapat dikategorikan dalam pekerjaan yang berat/sulit. Dimana waktu yang digunakan untuk menyelesaiakan sehelai kain batik untuk proses pencantingan rata-rata $5-6$ jam, dengan posisi duduk sedikit membungkuk agar proses pencantingan dapat dilakukan sesuai dengan keinginan mereka. Duduk dengan posisi membungkuk sepanjang waktu dapat cepat menimbulkan nyeri pada punggung dan kaki karena posisi yang dilakukakan adalah tidak nyaman sehingga hal inilah yang menyebabkan tingkat kelelahan lebih cepat timbul ditambah pekerjaan pencantingan adalah pekerjaan monoton dan berulang yang menyebabkan cepat jenuh.

Dari hasil analisis dengan bantuan software SPSS dapat diketahui bahwa tingkat kelelahan yang dialami oleh para pembatik berpengaruh signifikan terhadap produktivitas yang dihasilkan. Dimana semakin tingkat kelelahan yang dialami maka semakin rendah pula produktivitas yang dihasilkan.

\section{Daftar Pustaka}

[1] Renny, Septiari, et al., (2018). The Influence of Combining Sitting and Standing Position in Plastic Glass Packaging. Journal Engineering Science and Technology 13(2): 373-380. February.

[2] Renny, Septiari., (2020). The Correlation Between Physical Work Environment and Fatigue Level The Packaging Productivity of The Repetitive Task in Sitting Position. Journal of Engineering and Management in Industrial System, vol.8, No.1.

[3] Setyowati, L. 2014. Penyebab Kelelahan Kerja pada Pekerja Mebel. Jurnal Kesehatan Masyarakat Nasional Vol. 8 No. 8 Mei.

[4] Atiqoh, J., (2014). Faktor-faktor yang berhubungan dengan Kelelahan Kerja pada Pekerja Konveksi Bagian Penjahitan di CV Aneka Garment Gunungpati Semarang. Jurnal Kesehatan Masyarakat (e-Journal), Volume 2, Nomor 2, Februari. 
[5] Budiono, A., (2008). Bunga Rampai Higiene Perusahaan (Hiperkes) dan Kesehatan dan Keselamatan Kerja. Semarang: BP Universitas Diponegoro.

[6] ILO. 2013. The Prevention of Occupational Diseases. Geneva: International Labour Organization.

[7] Anoraga, P., (2009). Psikologi Kerja. Jakarta: Rieneka Cipta.

[8] Nurmianto, E., (2008). Ergonomi konsep dasar dan aplikasi. Surabaya: PT. Guna Widya.

[9] Tarwaka., (2014). Ergonomi Industri. Dasar-Dasar Pengetahuan Ergonomi dan Aplikasi di Tempat Tugas. Surakarta: Harapan Press.Ulfah, N. 2013. Model Kuantitatif Manajemen Kelelahan dan Beban Kerja untuk peningkatan Produktivitas Pekerja Penggilingan Padi. Jurnal Kesehatan Masyarakat Nasional Vol. 7, No. 10, Mei.

[10] Perwitasari, D., (2014). Faktor yang Berhubungan dengan Kelelahan Kerja Subjektif pada Perawat di Rsud Dr. Mohamad Soewandhie Surabaya. The Indonesian Journal of Safety, Health and Environment. Volume 1 No. 1, JanuariApril.

[11] Asberg and Furst, (2001). Dimensions of fatigue during radiotherapy--an application of the Swedish Occupational Fatigue Inventory (SOFI) on cancer patients. Acta Oncol.40(1):37-43.

[12] Sugiyono. (2014). Metode Penelitian Pendidikan Pendekatan Kuantitatif, Kualitatif, dan R\&D. Bandung: Alfabeta.

[13] Sekaran, U., (2010). Research Methods for Business (5th ed.). Chichester: John Wiley \& Sons.

[14] Muizzudin, A., (2013). Hubungan Kelelahan dengan Produktivitas Kerja pada Pekerja Tenun di PT. Alkatex Tegal. Unnes Journal of Public Health UJPH 2 (4).

[15] Arini, Shintia Yunita dan Endang Dwiyanti., (2015). Analisis Faktor yang Berhubungan dengan Kelelahan Kerja pada Pengumpul tol di Perusahaan Pengembang Jalan Tol Surabaya. The Indonesian Journal of Occupational Safety and Health Vol.4, No.2.

[16] Rofieq, Mochammad, et al., (2019). The Work Posture Evaluation at Assembly Work Station in MSEs of Silver Jewelry Handicraft with the REBA Method. Advanced in Intelligent System Research Vol.173. Proceeding of ICOEMIS 2019. 